\title{
Oral piercing and its implications on the health of oral tissues: Aesthetics or mutilation?
}

\author{
Nandini. DB ${ }^{1, *}$, Sumita Banerjee ${ }^{2}$, Ngairangbam Sanjeeta ${ }^{3}$, Apana Devi P. ${ }^{4}$, Praveen B Reddy ${ }^{5}$ \\ ${ }^{1}$ Professor \& Head, ${ }^{2,4}$ Assistant Professor, ${ }^{3}$ Associate Professor, Dept. of Oral Pathology \& Microbiology, ${ }^{5}$ Principal, Professor \& \\ HOD, Dept. of Oral and Maxillofacial Surgery, Regional Institute of Medical Sciences, Imphal, Manipur, India
}

*Corresponding Author:

Email: nanni29@rediffmail.com

\begin{abstract}
Oral piercing is an emerging trend among the youth in the present times. It is a popular yet bizarre method of body art and is considered a way to display one's cool personality. The piercing procedure is often painful and carries several complications of the oral tissues such as profuse bleeding, damage to the nerves and vital structures, infections, dislodgement and aspiration of the jewelry and chances of chocking. Dental practitioners are encountering increasing number of cases with various oral and dental complications of this practice. Thus, a comprehensive information about the possible risks and their management is the need of the hour.
\end{abstract}

Keywords: Adverse effects, Complications, Health risks, Lips, Mucosa, Oral piercing, Oral tissues, Tongue.

\section{Introduction}

Oral piercing is making holes in the oral tissues such as tongue, lips, gingiva, frenum or uvula so as to wear rings, studs or other jewelry in them. Piercing is very popular among the youth of the present generation. Though being considered trendy or bizarre, it has many adverse effects on wellbeing of oral tissues.

It is generally considered as a style or fashion statement among the adolescents and young adults of recent times. Piercing is considered as a way to display a cool and trendy personality or as a form of selfexpression and identification or as daring act while few do it for decoration or esthetics. ${ }^{1,2}$

It is also a part of some religious beliefs or traditional issues to denote marital status, or identity with a specific ethnic group dating back to antiquity. Some wear it as a memory of an event mostly traumatic., ${ }^{2,3}$

The prevalence of oral and/or peri-oral piercings varies from $0.8 \%$ to $12 \%$, resulting in a mean prevalence of $5.2 \%$ as reported by Hennequin et al. ${ }^{3}$ Oral piercing is more common in the oral tissues such as the tongue $(5.6 \%)$ which is the most frequent site followed by the lips $(1.5 \%)$, the cheeks $(0.1 \%)$ and rarely the uvula..$^{3-5}$ Other sites include floor of the mouth, gingiva, and frenums. ${ }^{5}$ Oral piercing is more prevalent in women $(5.6 \%)$ than men $(1.6 \%)$. The prevalence is said to be approximately four times higher among females when compared to males. ${ }^{3}$ However, few authors report piercing to be more common in males. $^{2}$

Jewelry used for piercing are usually made up of metals such as stainless steel, 14 or 18 karat gold, niobium, titanium, platinum, palladium or metal alloy. Recently synthetic materials like teflon, nylon or plastic have been used. Studs, rings and bar bells are commonly used. Shape and size of the jewelry is dependent on the tissues to be pierced and personal choice. ${ }^{1,6,7}$

Piercing is usually done manually using a hollow needle making a hole through the concerned tissue which is stabilized with the tissue forceps or by hand. Sometimes, cannulas are used where the hole is larger than the jewelry to be placed. Gunshot piercing or dermal punch have also been used recent in recent times.

Personnel performing piercing are usually unlicensed and nonprofessional with little knowledge on the local anatomy, sterilization procedures, subsequent complications and their management. In such a case the situation may be challenging. The risk of exposure to infection can be controlled during the piercing procedure by the use of sterile equipment and jewelry and rigorous adherence to aseptic technique. Tools and jewelry used in piercing should be sterilized in autoclaves, and non-autoclavable surfaces should be cleaned with disinfectant agents on a regular basis and between the clients. ${ }^{8}$ A procedure with proper technique would definitely reduce the complications. Hence educating the personnel about the correct procedure with emphasis on aseptic precautions and educating the patient about the post insertion care is very important.

The healing process of piercings is categorized into three stages ${ }^{8}$ :

1. The inflammatory phase, during which the wound is still open and bleeding, inflammation and tenderness are all to be expected;

2. The growth or proliferative phase, during which the body produces cells and protein to heal the puncture and the edges contract around the piercing, forming a tunnel of scar tissue called a fistula. This phase may last weeks, months, or longer than a year. 
3. The maturation or remodeling phase, as the cells in the adjacent vicinity of the piercing strengthen and stabilize. This stage takes months or years to complete.

4. The amount of time it typically takes a piercing to heal varies widely according to the site of placement and size of the piercing.

Possible complications of oral piercing: Complications of piercing have been classified into different categories by different authors. Dermata and Arhakis have summarized complications as complications during procedure, primary post-operative and secondary post-operative complications. ${ }^{(1)}$

Complications of piercing are also categorized depending on nature as acute or chronic, based on tissues as effects on soft tissue or hard tissue, and according to their systemic severity as local and systemic infections. ${ }^{6}$

1. Pain: Pain at the site of piercing is the most common and immediate complication of piercing. It could be due to lack of proper anesthesia or inflammation due unsterilized procedure..$^{9-11}$

2. Swelling, edema and inflammation: Swelling, edema and inflammation at the site of piercing are also immediate post piercing complications which are commonly reported. While swelling of the tongue is expected after piercing, in severe cases, it can swell significantly enough to close off the airway altogether. The resulting difficulty in breathing can be life-threatening. ${ }^{1}$

3. Local infection: Piercing invades the subcutaneous tissues with disruption in the integrity of mucosa. Thus, the microorganisms inhabiting the oral cavity may result in infections. ${ }^{12-14}$

4. Hemorrhage: Bleeding as a result of injury to the blood vessels while piercing tongue and the lips owing to its rich vascularity is very common complication. ${ }^{14-16}$ Hypotensive collapse in a medically compromised patient after significant bleeding due to oral piercing has also been reported. ${ }^{15}$

5. Increased salivation: Hyper salivation may be noticed during first few days following insertion of the jewelry which may disappear with due course of time. ${ }^{1}$

6. Nerve damage: Tongue piercing if not done with care may result in damage to the nerves resulting in impaired oral functions such as mastication, deglutition, speech, movement of tissues or taste alterations. It may sometimes lead to permanent numbness, speech impediments and the loss of taste. ${ }^{2,4}$

7. Gingiva and periodontal tissues: In case of gingival piercing, pyogenic granuloma, risk of periodontal disease, ulceration, and gingival recession can be encountered. There can be enlargement of piercing hole as well. Jewelry can act as a reservoir of periodontal pathogens like Aggregatibacter actinomycetemcomitans, Porphyromonas gingivalis, Prevotella intermedia, Tannerella forsythia and Treponema denticola. ${ }^{9,10}$

Friction from piercings along with their location and size would affect the oral tissues. ${ }^{4,10}$ Gingival recession in labial aspect of lower incisors is more often associated with lower lip piercing. ${ }^{4,10,17,18}$ Uneventful healing, keloids and hypertrophic scarring have also been reported. Sometimes the jewelry may be incorporated in the hypertrophic scar. ${ }^{12-14,19}$ Granulomatous reactions around the ornament, in which the body's defenses identify jewelry as a foreign body may also be observed.

8. Damage to teeth: Damage to the adjacent teeth such as attrition, abrasion, risk of dental caries, migration, mobility, chipping, fracture and loss of tooth have been reported in persons with oral piercings. Lesions may not only involve enamel but also dentin and sometimes damage pulp., ${ }^{4,10}$ Enamel cracks, fissures, groove shaped abrasions and recession were observed by Ziebolz et al. ${ }^{7}$ Tiny cracks can form and cause severe pain and may result in tooth fracture. ${ }^{20}$ Tongue and lip jewelry are more likely to cause damage to the teeth since they interfere in mastication, speech or other functions. ${ }^{4,10,13}$ Jewelry with soft or rubber ends cause less damage than those made with metals.

Dental trauma is more often seen with longer jewelry and is associated with longer duration of wear. Replacing jewelry with shorter ones may reduce the intensity of damage. ${ }^{4,10,13}$ Damage may be appreciable even within first year of use. ${ }^{10}$ Galvanic currents may result as a result of dissimilar metals in dental restorations and those used in jewelry. ${ }^{4,9}$ They may encourage the plaque and calculus build up leading to dental caries, periodontal problems, halitosis and possible infections. ${ }^{4,16}$ Gonzalez et al observed oral alterations in all patients, with dental mobility in $22 \%$ of cases, enamel fracture in $64 \%$, fissures in $62 \%$, periodontal bleeding in $2-12 \%$, pain in 34 $38 \%$, and pronunciation problems of certain words with $\mathrm{s}$, sh, th, ph, $\mathrm{t}$, and $\mathrm{v}$ in $67 \% .^{21}$

9. Aspiration or ingestion: If the jewelry gets dislodged it may cause choking.

10. Systemic complications: Piercing is also associated with the risk of transmission of blood borne diseases like HIV, Hepatitis B, C, D and G, Herpes simplex, Epstein Barr virus, tetanus, syphilis or tuberculosis. ${ }^{22,23}$ Bacterial infections with Staphylococcus aureus and Pseudomonas aeruginosa, $\beta$-hemolytic streptococcus have also been

Higher prevalence of colonization of Candida albicans is reported in young individuals with tongue piercing, in comparison to non-tongue- 
pierced matched individuals. (24) Risk of endocarditis. $^{13,14,25}$ Ludwig's angina, ${ }^{4,15}$ cerebral abscess $^{26}$ could be life threatening. Thrombophlebitis associated with pneumonitis after tongue piercing is also reported. ${ }^{27}$

11. Allergic reactions: Risk of allergic reaction or hypersensitivity to the materials like metal or polymer used for jewelry is also reported. European union has recommended $0.05 \%$ of nickel and 14-18 $\mathrm{K}$ gold to be used in jewelry used for piercing. ${ }^{1}$

12. Interference during treatment: Jewelry may interfere while administering anesthesia, while taking radiographs or teeth bleaching procedures. ${ }^{28,29}$ Oral jewelry may interfere during intubation procedure. Ultrasound, CAT and MRI images may be distorted by metal jewelry.

13. Post removal problems: If the person wants to discontinue the jewelry at a later date for some reason, reconstructive and regenerative techniques are not always successful. ${ }^{6}$

14. Athletes wearing oral piercings are advised to remove or wear mouth guards while indulging in sport activities such as boxing or wrestling. ${ }^{30}$

Guidelines to reduce post piercing complications: Few recommendations to minimize the risk of complications are as follows ${ }^{2}$ :

1. Use of sterile equipment and jewelry and rigorous adherence to aseptic technique.

2. Having cold liquid followed by soft diet in first 24 hours.

3. Application of ice to the pierced part for 30 minutes for at least 4-5 times a day to reduce swelling and edema.

4. Allow small pieces of ice to dissolve in the mouth.

5. Take an over-the-counter, non-steroidal antiinflammatory such as Ibuprofen or naproxen sodium according to the instructions.

6. Sleep with your head elevated above your heart during the first few nights.

7. Avoid oral rinse during first 24 hours followed by mouth rinse with $0.12 \%$ chlorhexidine $4-5$ times a day for 10 days or use any alcohol-free mouth washes.

8. Avoid use of alcohol, cigarettes and caffeine to promote epithelial cell turnover of oral mucosa for few days.

9. Avoid chewing of tobacco, nails and chewing gums or other foreign objects that could harbor bacteria to promote soft tissue healing.

10. Avoid excessive speaking to reduce damage to dentition or playing with the jewelry during healing can cause the formation of unsightly and uncomfortable scar tissue, migration, and other complications.

11. Use a new soft-bristled toothbrush and keep it clean
12. Replace piercing with a smaller one in the first few days to reduce irritation and allow the lesion to heal.

13. Maintaining a good oral hygiene, brushing the jewelry with soft brush gently to reduce accumulation of plaque.

14. Regular checkup for wellbeing of oral tissues around the jewelry as well as the piercing site itself.

Complications may result if the jewelry is inappropriately sized, improperly placed, or poorly manufactured. Hence, following things should also be considered $^{(31)}$

i. Jewelry must be the correct style for the anatomy and piercing placement;

ii. Jewelry must be accurately sized to the area. The longer jewelry that allows for initial swelling must be replaced with a shorter piece after swelling has dissipated to reduce the chance of harm to the teeth and oral structures.

iii. Check that threaded ends are on securely. Tighten them daily to ensure that your jewelry stays in place

iv. Balls made of polymer rather than metal can be worn on tongue to minimize the risk of damage to the teeth

v. Wearing a smaller ball on the underside of the tongue helps to reduce jewelry contact with the sublingual portion of the oral cavity

Proper placement is absolutely critical for health and comfort of oral tissues.

\section{Famous celebrities with oral and facial piercings}

Elaine Davidson is the "Most Pierced Woman" according to the Guinness World Records. In 2010, Davidson was reported to have a total of 6,725 piercings and by 2012, she has over $9,000 .^{32}$

German Rolf Buchholz, holds the Guinness World Record for the most pierced man and has a total of 453 piercings in various parts of his body. ${ }^{32}$ John Lynch, also known as Prince "John" Albert" from UK holds the record of "The man with the most body piercings" in 2008. He has a total of 241 piercings, including 151 in his head and neck. ${ }^{32}$ Alex Rosales from Argentina achieved the record of the person with the most facial piercings with 280 piercings, set a record with his face full of metal in February 2012. ${ }^{32}$

\section{Oral cavity and its unique features}

Oral cavity has unique feature like saliva that has antibacterial properties and coagulating factors which assist in faster healing and warding off infections. In addition, the cellular turnover rate for oral mucosa of the cheek is 25 days compared to $52-75$ days for skin. The short healing time of the average oral piercing provides a much smaller window of opportunity for exposure to infection than many other common piercings at other sites. However, oral cavity also has 
rich vascularity with a highly concentrated system of veins, arteries, and lymph vessels which may be damaged during piercing. Use of sterile equipment, aseptic procedure, appropriate jewelry, proper aftercare, qualified piercer with good knowledge of the anatomy, risks and their management will reduce the complications to a negligible number.

Dental associations such as American Dental association (ADA), British Dental Association (BDA), Irish Dental Association (IDA) and Swiss Dental Association (SSO) have pronounced against oral piercing through official documents and guidelines. However, in India it is yet to be enforced. ${ }^{2}$

\section{Conclusion}

Though oral piercing is done for esthetics, its adverse effects and complications are too many to be overlooked. Numerous case reports and reviews confirm the complications associated with oral piercing which may affect the wellbeing of oral tissues and may sometimes be life threatening as well. Educating the personnel performing the procedure about the aseptic technique and patients about the after care is the need of the hour to minimize the complications. Dentists should have knowledge about the complications and their management.

\section{References}

1. Dermata A, Arhakis A. Complications of oral piercing. Balk J Stom 2013; 17:117-121.

2. Inchingolo F, Tatullo M, Abenavoli FM, Marrelli M, Inchingolo AD, Palladino A et al. Oral piercing and oral diseases: A short time retrospective study Int J Med Sci. 2011;8(8):649-52.

3. Hennequin -Hoenderdos NL, Slot DE, Van der Weijden GA. The prevalence of oral and peri-oral piercings in young adults: A systematic review. Int J Dent Hyg, 2012;10:223-8.

4. De Moor RJ, De Witte AM, Delmé KI, De Bruyne MA, Hommez GM, Goyvaerts D. Dental and oral complications of lip and tongue piercings. Br Dent $\mathrm{J}$. 2005;199:506-9.

5. Mini Guide: Types of oral piercings. Available at https://www.tattoodo.com/a/2016/04/mini-guide-typesof-oral-piercings/

6. Plastargias I, Sakellari D. The Consequences of tongue piercing on oral and periodontal tissues. ISRN Dentistry Volume 2014, Article ID 876510,6 pages

7. Ziebolz D, Hildebrand A, Proff P, Rinke S, Hornecker E, Mausberg RF. Long-term effects of tongue piercing -A case control study. Clin Oral Invest 2012;16:231-7.

8. Angel, Elayne (2009). The Piercing Bible: The definitive guide to safe body piercing. The Crossing Press. ISBN 158091-193-5.

9. Scully C, Chen M. Tongue piercing (oral body art). Br J Oral Maxillofac Surg, 1994;32:37-8.

10. Campbell A, Moore A, Williams E, Stephens J, Tatakis D $\mathrm{N}$. Tongue piercing: Impact of time and barbell stem length on lingual gingival recession and tooth chipping. J Perio 2002;73:289-97.

11. Farah CS, Harmon DM. Tongue piercing: Case report and review of current practice. Aust Dent J, 1998;43:387-9.
12. Escudero-Castaño N, Perea-García MA, Campo-Trapero J, Cano-Sánchez, Bascones-Martínez A. Oral and perioral piercing complications. Open Dent J. 2008;4:133-6.

13. Vieira EP, Ribeiro AL, Pinheiro Jde J, Alves Sde M Jr. Oral piercings: Immediate and late complications. J Oral Maxillofac Surg, 2011;69:3032-7.

14. Maheu-Robert LF, Andrian E, Grenier D. Overview of complications secondary to tongue and lip piercings. J Can Dent Assoc, 2007;73:327-31.

15. Hardee PSGF, Mallya L R, Hutchinson IL. Tongue piercing resulting in hypotensive collapse. Br Dent $\mathrm{J}$ 2000;188:657-58.

16. Shacham R, Zaguri A, Librus HZ, Bar T, Eliav E, Nahlieli O. Tongue piercing and its adverse effects. Oral Surg Oral Med Oral Pathol Oral Radiol Endod, 2003; 95:274-6.

17. Sardella A, Pedrinazzi M, Bez C, Lodi G, Carrassi A. Labial piercing resulting in gingival recession. A case series. J Clin Periodontol, 2002;29:961-3.

18. Levin L. Alveolar bone loss and gingival recession due to lip and tongue piercing. N Y State Dent J. 2007:73(4):48 50.

19. Pía López-Jornet, Cristina Navarro-Guardiola, Fabio Camacho-Alonso, Vicente Vicente-Ortega, Josefa YánezGascon. Oral and facial piercings: A case series and review of the literature. Int J Dermatol 2006;45(7):805-9.

20. Brennan M, O'Connell B, O'Sullivan M. Multiple dental fractures following tongue barbell placement: A case report. Dent Traumatol, 2006;22:41-3.

21. Levin L, Zadik Y. Oral Piercing: Complications and side effects. Am J Dent 2007:20 (5): 340-44.

22. Levin L, Zadik Y, Becker T. Oral and dental complications of intra-oral piercing. Dent Traumatol 2005:21(6):341-3.

23. American Dental Association. ADA Statement on Intraoral/Perioral Piercing. Accessed May 14, 1999. Available http://www.ada.org/prof/resource/positions/statements/pie rcing.asp

24. Yehuda Z, Saar B, Estella D, Vadim S, Clariel I, Tamar H. Colonization of Candida: prevalence among tonguepierced and non-pierced immunocompetent adults. Oral Dis 2010;16(2):172-5.

25. Currie-McGhee, Leanne K. (2006). Tattoos and body piercing. Lucent Overview Series. Lucent Books. p. 11. ISBN 1-59018-749-0.

26. Martinello R A, Cooney E L. Cerebellar brain abscess following tongue piercing. Clin Infect Dis 2003;36:E32E34.

27. Nicolas J, Soubeyrand E, Joubert M, Labbé D, Compère $\mathrm{JF}$, Verdon R, Benateau H. Thrombophlebitis of the sigmoid sinus after tongue piercing: A case report. J Oral Maxillofac Surg, 2007;65(6):1232-4.

28. Ranalli DN, Rye LA. Oral health issues for woman athletes. Dent Clin North Am, 2001; 45(3):523-39.

29. Kuczkowski KM, Benumof JL. Tongue piercing and obstetric anesthesia: Is there cause for concern? J Clin Anesth 2002;14(6):447-8.

30. Academy of General Dentistry. Dentists tell athletes keep the mouth guard, take out the barbell. January 2012. Accessed April 21, 2014.

31. "APP Information". Minimum jewelry standards for detailed jewelry material and design specifications. www.safepiercing.org. Association of Professional Piercers. Retrieved 18 May 2012.

32. These people take piercing as an extremely weird hobby and the results? Mind Boggling!!, 
https://www.wereblog.com/world-most-extreme-piercing; 2017 [accessed 15.05.2017] 